\title{
On Ternary Quadratic Diophantine Equation $8 \mathrm{x}^{2}+$ $8 y^{2}-15 x y=40 z^{2}$
}

\author{
Dr. P. Jayakumar ${ }^{1}$, J. Meena ${ }^{2}$ \\ ${ }^{1}$ Professor of Mathematics, Periyar Maniammai University, Vallam, Thanajvur-613 403,Tamil Nadu, India \\ ${ }^{2}$ Ph.D. Scholar, Assistant Professor of Mathematics, A.V.V.M. Sri Pushpam College (Autonomous), Poondi -613 503, \\ Thanajvur, Tamil Nadu, India
}

\begin{abstract}
Five different methods of the non-zero integral solutions of the ternary quadratic homogeneous Diophantine equation 8x ${ }^{2}+$ $8 y^{2}-15 x y=40 z^{2}$ are obtained. Some interesting relations among the special numbers and the solutions are exposed.
\end{abstract}

Keywords: Ternary Quadratic, homogenous cone, integer solutions, special numbers.

\section{Mathematics Subject Classification: 11D09}

\section{Notations used}

$t_{m, n}$ - Polygonal number of rank $n$ with sides $m . \mathrm{Ct}_{m, n}$ - Centered Polygonal number of rank n with sides $m s_{n}-S_{t a r}$ number $p_{n}-$ Pronic number $\mathrm{G}_{\mathrm{n}}$ - Gnomonic number

\section{Introduction}

The number theory is queen of Mathematics. In particular, the Diophantine equations have a blend of attracted interesting problems. For an extensive review of variety of problems, one may refer to [3-12]. In this work, we are observed another interesting five different methods of the non-zero integral solutions the ternary quadratic homogeneous Diophantine equation $8 x^{2}+8 y^{2}-15 x y=40 z^{2}$. Further, some elegant properties among the special numbers and the solutions are observed.

\section{Method of Analysis}

The ternary quadratic homogeneous Diophantine equation to be solved is

$$
8 x^{2}+8 y^{2}-15 x y=40 z^{2}
$$

The substitution of linear transformations

in (1) leads to

$$
x=\mathrm{u}+\mathrm{v} \text { and } \mathrm{y}=\mathrm{u}-\mathrm{v}(\mathrm{u} \neq \mathrm{v} \neq 0)
$$

$$
u^{2}+31 v^{2}=40 z^{2}
$$

The above equation is solved through different methods and different patterns of integer solution to (1) are obtained.

\subsection{Pattern: I}

Write 40 as

$$
\begin{gathered}
40=(3+i \sqrt{31})(3-i \sqrt{31}) \\
\text { Assume } z=a^{2}+31 b^{2} \text {, where } a, b>0
\end{gathered}
$$

Using (4) and (5) in (3) and applying the method of factorization, define

$$
(u+i \sqrt{31} v)=(3+i \sqrt{31})(a+i \sqrt{31} b)^{2}
$$

Equating the real and imaginary parts, we have

$\mathrm{u}=\mathrm{u}(\mathrm{a}, \mathrm{b})=3 \mathrm{a}^{2}-93 \mathrm{~b}^{2}-62 \mathrm{ab}$

$v=\mathrm{v}(\mathrm{a}, \mathrm{b})=\mathrm{a}^{2}-31 \mathrm{~b}^{2}+6 \mathrm{ab}$

Substituting the above $u$ and $v$ in equation (2) the value of $x$ and $\mathrm{y}$ are given by

$x=\mathrm{x}(\mathrm{a}, \mathrm{b})=4 \mathrm{a}^{2}-124 \mathrm{~b}^{2}-56 \mathrm{ab}$

$$
y=y(a, b)=2 a^{2}-62 b^{2}-68 a b
$$

Thus (5) and (7) represents non-zero distinct integral solutions of (1) in two parameters.

\section{Properties:-}

1. $x(\mathrm{a}, 1)-4 \mathrm{t}_{4, \mathrm{a}}+\mathrm{G}_{28 \mathrm{a}} \equiv 0(\operatorname{Mod} 123)$

2. $\mathrm{z}(\mathrm{a}, \mathrm{a}+1)-32 \mathrm{t}_{4, \mathrm{a}}-\mathrm{G}_{31 \mathrm{a}} \equiv 0(\operatorname{Mod} 32)$

3. $y(1, \mathrm{~b})-62 \mathrm{t}_{4, \mathrm{~b}}+\mathrm{G}_{34 \mathrm{~b}} \equiv 0(\operatorname{Mod} 3)$

4. $x(\mathrm{a}, 1)+\mathrm{z}(\mathrm{a}, 1)-5 \mathrm{t}_{4, \mathrm{a}}+\mathrm{G}_{28 \mathrm{a}} \equiv 0(\bmod 92)$

5. y $(2, \mathrm{~b})-\mathrm{x}(2, \mathrm{~b})+186 \mathrm{t}_{4, \mathrm{~b}}+\mathrm{G}_{124 \mathrm{~b}} \equiv 0(\operatorname{Mod} 7)$

\subsection{Pattern: II}

Consider (3) as $\mathrm{u}^{2}-9 \mathrm{z}^{2}=31\left(\mathrm{z}^{2}-\mathrm{v}^{2}\right)(8)$

Write (8) in the form of ratio as

$\frac{u+3 z}{z-v}=31 \frac{(z+v)}{u-3 z}=\frac{\alpha}{\beta}, \beta \neq 0$

This is equivalent to the following two equations

$-\alpha u+31 \beta v+z(31 \beta+3 \alpha)=0$

$\beta \mathrm{u}+\alpha v+\mathrm{z}(3 \beta-\alpha)=0$

On employing the method of cross multiplication, we get.

$u=-3 \alpha^{2}+93 \beta^{2}-62 \alpha \beta$

$v=-\alpha^{2}+31 \beta^{2}+6 \alpha \beta(9)$

$\mathrm{z}=-\alpha^{2}-31 \beta^{2}(10)$

Substituting the values of $u$ and $v$ from (9) in (2) the nonzero distinct integer values of $\mathrm{x}, \mathrm{y}$ are given by

$x=x(\alpha, \beta)=-4 \alpha^{2}+124 \beta^{2}-56 \alpha \beta$

$y=y(\alpha, \beta)=-2 \alpha^{2}+62 \beta^{2}-68 \alpha \beta(11)$

Thus (10) and (11) represent the non- zero distinct integer solution of equation (1) in two parameters. 


\section{International Journal of Science and Research (IJSR) \\ ISSN (Online): 2319-7064}

Index Copernicus Value (2013): 6.14 | Impact Factor (2014): 5.611

\section{Properties:-}

1. $z(\beta+3, \beta+3)+32 \mathrm{t}_{4, \beta}+\mathrm{G}_{96 \beta} \equiv 0(\operatorname{Mod} 287)$

2. $y(3,2 \beta)-248 \mathrm{t}_{4, \beta}+\mathrm{G}_{204 \beta} \equiv 0(\operatorname{Mod} 17)$

3. $x(\alpha, 1)+4 \mathrm{t}_{4, \alpha}+\mathrm{G}_{23 \alpha} \equiv 0(\operatorname{Mod} 125)$

4. $x(2, \alpha)+\mathrm{y}(2, \alpha)-186 \mathrm{t}_{4, \alpha}+124 \mathrm{G}_{\alpha}+23=1$.

5. $x(3,2 \beta)-\mathrm{y}(2,3 \beta)+t_{150 \beta}+151 \mathrm{p}_{\beta}+151 \mathrm{t}_{4, \beta}+28=0$

Note:-

(8) also be expressed in the form of ratio in three different wags as follows.

(1) $\frac{(u+3 z)}{31(z+v)}=\frac{z-v}{u-3 z}=\frac{\alpha}{\beta}, \beta \neq 0$.

(2) $\frac{(u+3 z)}{z+v}=\frac{31(z-v)}{(u-3 z)}=\frac{\alpha}{\beta}, \beta \neq 0$.

(3) $\frac{(u+3 z)}{31(z-v)}=\frac{z+v}{u-3 z}=\frac{\alpha}{\beta}, \beta \neq 0$.

Repeating the analysis as above, we get different pattern of solution to (1).

\subsection{Pattern: III}

Rewrite (3) as $31 v^{2}=40 z^{2}-u^{2}(12)$

Write 31 as,

$31=(2 \sqrt{10}+3)(2 \sqrt{10}-3)(13)$

Let $\mathrm{v}=40 \mathrm{a}^{2}-\mathrm{b}^{2}(14)$

Using (13) and (14) in (12) and employing the method of factorization, we write

$(2 \sqrt{10} \mathrm{z}+\mathrm{u})=(2 \sqrt{10}+3)(2 \sqrt{10} \mathrm{a}+\mathrm{b})^{2}$

Equating the rational and irrational parts, we have $\mathrm{z}=\mathrm{z}(\mathrm{a}, \mathrm{b})=40 \mathrm{a}^{2}+\mathrm{b}^{2}+6 \mathrm{ab}(15) \mathrm{u}=\mathrm{u}(\mathrm{a}, \mathrm{b})=120 \mathrm{a}^{2}+3 \mathrm{~b}^{2}+$ $80 \mathrm{ab}$ (16) Substituting (14) \& (16) in (2), the values of $\mathrm{x}$ and $\mathrm{y}$ are

$\mathrm{x}=\mathrm{x}(\mathrm{a}, \mathrm{b})=160 \mathrm{a}^{2}+2 \mathrm{~b}^{2}+80 \mathrm{ab}$

$\mathrm{y}=\mathrm{y}(\mathrm{a}, \mathrm{b})=80 \mathrm{a}^{2}+4 \mathrm{~b}^{2}+80 \mathrm{ab}$

Thus (17) and (15) represent the integer solution to (1)

\section{Properties:}

1. $\mathrm{x}(\mathrm{a}, 1)-160 \mathrm{t}_{4, \mathrm{a}}-\mathrm{G}_{40 \mathrm{a}} \equiv 0(\operatorname{Mod} 3)$

2. $\mathrm{z}(3 \mathrm{a}, 1)-360 \mathrm{t}_{4, \mathrm{a}}-\mathrm{G}_{9 \mathrm{a}} \equiv 0(\operatorname{Mod} 2)$

3. $x(a, 2)-z(a, 2)-160 t_{4, a}-G_{80 a} \equiv 0(\operatorname{Mod} 9)$

4. $\mathrm{y}(\mathrm{a}, 3)-80 \mathrm{t}_{4, \mathrm{a}}-\mathrm{G}_{120 \mathrm{a}} \equiv 0(\operatorname{Mod} 37)$

5. $y(a, a)-164 t_{4, a}=0$

\section{Conclusion}

In this paper, we have presented different patterns of integer solutions to the ternary quadratic equation $8 x^{2}+8 y^{2}-15 x y$ $=40 \mathrm{z}^{2}$ representing the cone. As this Diophantine equation is rich in variety, one may attempt to find integer solutions to other choices of equations along with suitable properties.

\section{References}

[1] Dickson, L.E., History of theory of numbers, Vol.11, Chelsea publishing company, New -York (1952).

[2] Mordell, L.J., Diophantine equation, Academic press, London (1969)
[3] Jayakumar. P, Sangeetha,K "Lattice points on the cone $\mathrm{x}^{2}+9 \mathrm{y}^{2}=50 \mathrm{z}^{2}$, International Journal of SciencandResearch, Vol (3), Issue 12, 20-22 (December -2014)

[4] Jayakumar P, Kanaga Dhurga,C," On Quadratic Diophantine equation $x^{2}+16 y^{2}=20 z^{2, " ~ G a l o i s ~}$ J.Maths, 1(1) (2014), 17-23.

[5] Jayakumar. P, Kanaga Dhurga. C, "Lattice points on the cone $x^{2}+9 y^{2}=50 z^{2}$ " Diophantus J. Math, 3(2) (2014), 61-71

[6] Jayakumar. P, Prabha. S "On Ternary Quadratic Diophantine equation $\mathrm{x}^{2}+15 \mathrm{y}^{2}=14 \mathrm{z}^{2}$ " Archimedes J. Math., 4(3) (2014), 159-164.

[7] Jayakumar, P, Meena, J "Integral solutions of the Ternary Quadratic Diophantine equation : $x^{2}+7 y^{2}=$ $16 z^{2 "}$ International Journal of Science and Technology, Vol.4, Issue 4, 1-4, Dec 2014.

[8] Jayakumar. P, Shankarakalidoss, G "Lattice points on Homogenous cone $\mathrm{x}^{2}+9 \mathrm{y}^{2}=50 \mathrm{z}$ " International journal of Science and Research, Vol (4), Issue 1, 2053-2055, January -2015

[9] Jayakumar. P,Shankarakalidoss.G "Integral points on the Homogenous cone $x^{2}+y^{2}=10 z^{2}$ " International Journal for Scienctific Research and Development, Vol (2), Issue 11, 234-235, January -2015

[10] Jayakumar.P, Prabha.S "Integral points on the cone $x^{2}$ $+25 \mathrm{y}^{2}=17 \mathrm{z}^{2}$ " International Journal of Science and Research Vol(4), Issue 1, 2050-2052, January-2015.

[11] Jayakumar.P, Prabha. S, "Lattice points on the cone $x 2$ $+9 \mathrm{y} 2=26 \mathrm{z} 2$ "International Journal of Science and Research Vol (4), Issue 1, 2050-2052, January -2015

[12] Jayakumar. P, Sangeetha. K, "Integral solution of the Homogeneous Biquadratic Diophantine equation with six unknowns: $\left(\mathrm{x}^{3}-\mathrm{y}^{3}\right) \mathrm{z}=\left(\mathrm{W}^{2}-\mathrm{P}^{2}\right) \mathrm{R}^{4}$ "International Journal of Science and Research, Vol(3), Issue 12, 1021-1023 (December-2014)

\section{Author Profile}

P. Jayakumar received the B. Sc, M.Sc degrees in Mathematics from Madras University in 1980 and 1983 and the M. Phil, Ph.D degrees in Mathematics from Bharathidasan University , Thiruchirappalli in 1988 and 2010. Who is now working as Professor of Mathematics, Periyar Maniammai University, Vallam, Thanajvur-613 403, Tamil Nadu,India

J. Meena received the B. Sc, M.Sc degrees in Mathematics from Bharathidasan University, Thiruchirappalli in 2008 and in 2010 and the M.Phil.,degreein Mathematics from Prist University, Thanjavur in 2013. Who is now working as Assistant Professor of Mathematics, A.V.V.M Sri Pushpam College Poondi (Autonomous), Thanjavur (District) - 613 503, Tamil Nadu, India. 